\title{
Features of creating multi-time thematic animations of the Arctic environment pollution on the example of Novaya Zemlya
}

\author{
Andrey Medvedev ${ }^{\mathrm{a}, *}$, Natalia Alekseenko ${ }^{\mathrm{b}}$, Maria Arsentyeva ${ }^{\mathrm{b}}$ \\ ${ }^{a}$ Institute of geography Russian Academy of Sciences, a.a.medvedeff@gmail.com, \\ ${ }^{b}$ Lomonosov Moscow State University, valtuz@mail.ru, arsentyevamv@gmail.com \\ * Corresponding author
}

Keywords: Multi-time animation, nuclear pollution, Arctic, interactive visualization

\begin{abstract}
:
The Arctic region is currently at the next stage of increased interest not only from the Arctic States, but also from the entire world community. The main pollutants in the region are oil and gas products, heavy metals, chemical and radioactive contamination. The Arctic region of the Russian Federation has experienced a strong anthropogenic impact of radionuclides due to the use of nuclear energy. The main source of pollution is nuclear testing. About 132 tests were conducted on Novaya Zemlya, including 87 atmospheric, 3 underwater and 42 underground tests. Another source of radioactive contamination is the operation of the naval and civil nuclear fleet, as well as nuclear power plants (on the Kola Peninsula and in Bilibino). Until 1963, most of the tests were carried out in the atmosphere and under water, but after the signing of the Moscow Treaty on August 5, 1963, which prohibits the testing of nuclear weapons in three environments (under water, in the atmosphere and outer space), all tests were carried out underground, in tunnels and wells.
\end{abstract}

The object of research and mapping is the territory of the Novaya Zemlya archipelago and the nuclear test site located on it. On the territory of the nuclear test site constantly there was an assessment of the radioecological situation. The scientific community is interested in the processes taking place on the New Earth. The territory of the archipelago is constantly involved in various Arctic programs aimed at monitoring the level of environmental pollution and reducing the number of sources of pollution.

The aim of this work is to create multi-time animations of nuclear tests and the results of radionuclide pollution. These animated cartographic images differ not only in their time scales, but also a large set of qualitative and quantitative characteristics that characterize the results of anthropogenic influence.

As sources for creation of cartographic animations were: field data, remote sensing data (RS), Open sources, marine navigation maps, DEM's (AsterDem, ArcticDem, GEBCO), meteorological data, thematic maps (including atlases), topographic maps, literary sources. The main part of the information about Novaya Zemlya archipelago was taken from the works of the Arctic marine complex expedition, which are devoted to the nature, history, archeology and culture of the archipelago. To obtain complete information about the explosions and their energy release ranges, additional open sources were used, from which it is possible to learn about the type of explosion, its power and location (geographical coordinates).

Dynamic geo-imagery was developed and established by the following method: study of object mapping and the collection of primary spatial data - creation script dynamic geo-imagery - the creation of a geodatabase of research - the creation of the thematic maps and layout of geo-imagery in the graphic editor - create animations with different time scales.

During the creation of cartographic animations based on the collected data, a multi-time multi-scale cartographic animation was developed, which allowed using the original graphical solution to visualize three interconnected time scales, which allowed to visualize the processes of infiltration and propagation of radioactive inert gases. 